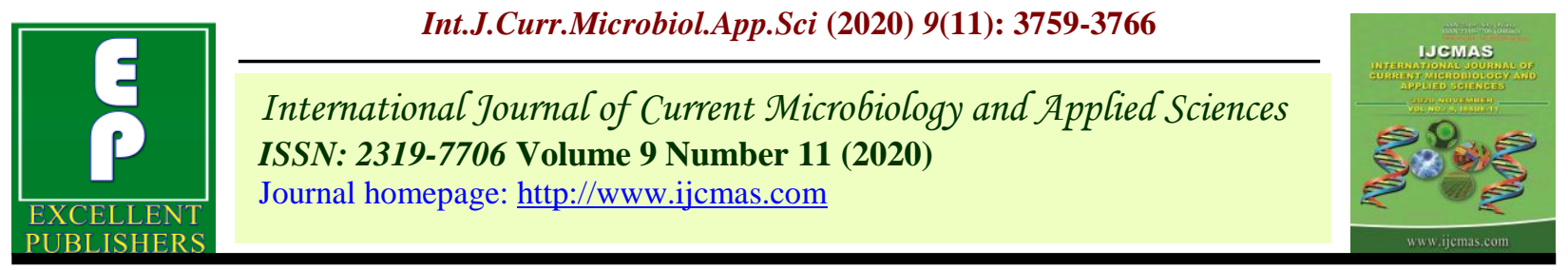

Review Article

https://doi.org/10.20546/ijcmas.2020.911.451

\title{
Improving Plant Growth and Quality of Plant-Products: An Interplay of Plant-microbe Interaction
}

\author{
Tabish Shabir ${ }^{1}$, Zahoor A. Baba ${ }^{2}$, Shakeel A. Dar ${ }^{3}$ and Amjad M. Husaini ${ }^{{ }^{*}}$ \\ ${ }^{1}$ Genome Engineering and Societal Biotechnology Lab, Division of Plant Biotechnology, \\ SKUAST-K, Shalimar, Jammu \& Kashmir, India \\ ${ }^{2}$ Division of Basic Sciences, ${ }^{3}$ Division of Environmental Sciences, SKUAST-K, Jammu \& \\ Kashmir, India \\ *Corresponding author
}

\section{A B S T R A C T}

\section{Keywords}

Biofertilizer, Organics, Agriculture, Siderophores, Disease control, Mycorrhiza

Article Info

Accepted:

25 October 2020

Available Online:

10 November 2020
For intensified productivity, plant-microbe interplays must be taken into consideration for meeting the requirements of sample food. Unfortunately, researchers turn a blind eye to beneficial plant-microbe interactions in breeding strategies even though plant-associated microorganisms satisfy the indispensable functions of the ecosystem for the plants. Microbial inoculants developed through the plant-microbe interactions may prove to be a promising key for viable, nature-friendly agriculture, leading to improved quality of plant products. The overall impact of such plant-microbe interactions can have implications for plant growth and fitness, carbon sequestration, nutrient cycling, and may influence plant community rejoinders to global environmental changes. Quality improvement of the plant products will score in prodigious progress in agriculture. Plant-microbe interactions greatly influence plant health and quality since these micro organisms are able to aid the host plant in dealing with drought, stress conditions, etc. thus, enhancing the quality of many plant food products would contribute significantly to human nutrition and health.

\section{Introduction}

In a natural ecosystem, plant-microbe interplay is the key to primary productivity. The association between plant and microbe is highly disparate as plants thrive and adept at sensing changes in the environment, integrating multiple signals, and modulating growth and development under varying environmental conditions. Soil is the main pool of microorganisms and microbes. These colonize plants epiphytically orendophytically and clout these either with benefits or pathogenic consequences. Microorganisms residing in the solum plays a considerable role in ecosystem functioning. The plant-microbe interactions take place above and below ground, however these interactions are more complex below ground than above the soil surface (Bais et al., 2004). Plant growth promoting rhizobacterial (PGPR's) primary mechanisms can be divided into two categories, i.e., direct and indirect. Phosphate solubilization, phytohormone and siderophore production are examples of direct growth promotion (Kloepper et al., 1989; Glick et al., 1995; Ayyadurai et al., 2007), while indirect growth promotion occurs by inhibiting the 
growth of plant pathogens (Glick and Bashan 1997; Persello-Cartieaux et al., 2003; Ravindra Naik et al., 2008). Microbial abundance and diversity are found to be reduced under soil perturbations and pollution. The machination of these interactions is vital for understanding the ecological role of microbial population and viable agriculture. The benefits of using these interactions are many-fold.

\section{Microbiome-the second plant genome}

Several fungi and bacteria are present in the rhizosphere, and make a dynamic community known as 'microbiome'. It may consist of ten times more genes than typical plant genomes. The rhizosphere is operationally described in terms of a concentration gradient between the root surface and the bulk soil. Microbes present in the rhizosphere thus have a prominent role to play as sensitive ecological indicators. These microorganisms interact with each other and with plants; such interactions may be friendly or hostile as described by a broad range of scientific studies (Saharan and Nehra, 2011; Nadeem et al., 2013; Schikora, 2018; Ding et al., 2019; Wille et al., 2019). The nature of the interaction is determined by the type of microbial species as well as the mechanism of action adopted by the microbiome (Nadeem et al., 2014). Root exudates provide a nutritional source to several bacteria inhabiting the rhizosphere, which take part in nutrient cycling in soil (Jaeger et al., 1999). Microorganisms present in the rhizosphere play essential roles in the ecological fitness of their plant host. Rhizosphere functioning is known to be markedly influence plant fitness and soil quality because microbial developments in such an environment can help the host plant adapt to stress conditions concerning water and mineral deficit, and the presence of soil-borne plant pathogens (Bowen and Rovira, 1999).
An essential factor for all successful plantmicrobe interactions is the competence to colonize the plant habitats. Plant roots initiate crosstalk with soil microbes by producing signals that are recognized by microbes, which in turn produce signals to initiate colonization (Bais et al., 2006). Plants receive nutrients from two natural sources: Organic matter and minerals and chemical fertilizers. Farmers only rely on chemical fertilizer, which deteriorates the quality of soil and increases production cost. Bacterial inoculation provides $\mathrm{N}, \mathrm{P}$, and growth hormones and makes plant healthy and less susceptible to pathogen attacks. It is also evident from the literature that microbes interact negatively with plants and negatively impact plant growth. Such negative impacts are due to their pathogenic nature that causes the onset of various diseases or by producing compounds that are harmful to plants (Xiong and Fuhrmann 1996; Pamp and TolkerNeilsen, 2007; Vacheron et al., 2013).

\section{Beneficial microorganisms and growth promotion}

Microorganisms associated with plants are responsible for their nutrition (i.e., microorganisms that can increase the supply of mineral nutrients to the plant). Secondly, a group of microorganisms stimulates plant growth indirectly by preventing the growth or activity of pathogens. Such microorganisms are referred to as 'biocontrol agents' and are well-documented. A third group involves those microorganisms responsible for direct growth promotion, for instance, by the production of phytohormones. There has been a large body of literature describing potential uses of plant-associated bacteria as agents stimulating plant growth and managing soil and plant fitness (Welbaum et al., 2004).

Plant growth promotion, which directly affects the plant's end products, can be 
achieved by the direct interaction between favourable microbes and their host plant and indirectly due to their antagonistic activity against plant pathogen. There are several plant growth promoting rhizobacterial inoculants currently commercialized, which promote growth and development through at least one of the following mechanisms:

\section{Biostimulation}

One of the direct growth promotion mechanisms of beneficial microorganismsis by producing phytohormones like indole acetic acid, abscisic acid, cytokinins, gibberellins, and ethylene. These phytohormones enhance plant growth by their positive effect on cell division, cell enlargement, seed germination, root formation, and stem elongation (Khalid et al., 2006). Many Pseudomonas, Bacillus, and Azospirillum spp. produce cytokinin and gibberellins (Gamalero and Glick, 2011), which in turn cause positive effects on plant biomass(Spaepen et al., 2009). Auxins are quantitatively the most abundant phytohormones secreted by Azospirillum. It is generally agreed that their production rather than nitrogen-fixation is the primary factor responsible for the stimulation of rooting and hence enhanced plant growth (Bloemberg et al., 2001).

\section{Biofertilization}

Many bacterial endophytes have attracted considerable attention for their capacity to promote plant growth and improved nutrient acquisition. The mode of action is by directly helping in the nutrient uptake or indirectly influencing the root growth and morphology (Vessey, 2003). Biofertilization accounts for approximately $65 \%$ of the nitrogen supply to crops worldwide (Bloemberg and Lugtenberg, 2001).

\section{Siderophore production}

The production of low-molecular-weight ferric-chelating compounds siderophores directly increase the iron availability for a plant (Robin et al., 2008) and indirectly protect the plant from pathogenic organisms (Singh et al., 2010b). Siderophores play an important role in the iron nutrition of plants (Jin et al.,2006).

\section{Volatiles}

Plant associated microorganisms have been shown to activate plant host defense when symbiotic interaction becomes unproductive (Parniske et al., 1991). Both plants and microbes can produce a range of volatile organic compounds- volatiles. While the volatile plant hormones such as ethylene, methyl jasmonate, and methyl salicylate function as airborne signals in mediating plant communications, several bacterial volatiles play a vital role in biocontrol $(\mathrm{HCN})$ or induce systemic resistance in plants. The indirect mechanism includes disease suppression occurring by the production of antibiotics. The antibiotics, in addition to suppressing the pathogen, also induce systemic resistance in the plant. The synergistic interaction between antibiotics and ISR further increases resistance against pathogens (Jha et al., 2011). Early recognition of the aggressor by the plant is one of the mechanisms involved in the elicitation of plant defense reactions (Lugtenberg et al., 2002).

\section{Pathogen inhibition}

In the tussle for establishment and continuance in the niche, bacteria use various tactics: a) Competition: For biocontrol action, it occurs when the antagonist directly competes with pathogens for the resources (competition for nutrients, especially for 
carbon). Competition for trace elements, such as iron, copper, zinc, magnesium, etc...also take place; b) Antagonism: It includes antibiosis, i.e., the inhibition of microbial growth by diffusable antibiotics and volatile compounds, toxins, and biosurfactants that may involve the production of extracellular cell wall- degrading enzymes such as chitinases and glucanases (Compant et al., 2005). Excretion of chitinases and glucanases by species of Trichoderma and Streptomyces has also been shown to play an important role in mycoparasitism of phytopathogenic fungi (Whipps, 2001).

\section{Mycorrhizal fungi}

The microbes coordinate their metabolic activity and gene expression according to the density of their local population, a process called quorum sensing. Mycorrhizal fungi are the members of the rhizosphere mutualistic microsymbiont populations known to carry out many critical ecosystem functions. These are the improvement of plant establishment and soil structure, enhancement of plant nutrient uptake, plant protection against cultural and environmental stresses (Smith and Read, 1997). Mycorrhiza establishment is known to modify several aspects of plant physiology, including mineral nutrient composition, hormonal balance, $\mathrm{C}$ allocation patterns, etc. (Harley and Smith 1983; Smith et al., 1994). Two major groups of microorganisms that interact with mycorrhizal fungi in the rhizosphere environments arethe saprophytes and the symbionts. Both of them comprise detrimental, neutral, and beneficial bacteria and fungi.

Mycorrhizal fungi also interact with both symbiotic and free-living nitrogen (N2)-fixing bacteria (Barea 1997).The microbial interactions in the rhizosphere of mycorrhizal plants improve plant fitness and soil quality, critical issues for sustainable agricultural development, and ecosystem functioning. Biologically active substances such as amino acids, plant hormones, vitamins, and other organic compounds can be produced by soil microorganisms, stimulating the growth rates of mycorrhizal fungi. It is noteworthy that antibiotic-producing Pseudomonas spp. (Vazquez et al., 2000) did not interfere with mycorrhiza formation or functioning. Interestingly, some rhizobial and pseudomonad bacteria adhere to the hyphae of mycorrhizal fungi, which appear to be a vehicle for root colonization by these bacteria (Bianciotto et al., 2000). The well-known activities of nitrogen-fixing bacteria and phosphate-solubilizing microorganisms improving the bioavailability of the major plant nutrients $\mathrm{N}$ and $\mathrm{P}$ are very much enhanced in the rhizosphere of mycorrhizal plants where synergistic interactions of such microorganisms with mycorrhizal fungi have been demonstrated.

The inoculation of mycorrhizal fungi has been shown to improve nodulationandN2 fixation. It should be noted that several studies have demonstrated that microbial antagonists of fungal pathogens, either fungi or PGPR exert no antimicrobial effect against mycorrhizal fungi (Calvet et al., 1993).Several microbial combinations are reported to improve either plant development, nutrient uptake, $\mathrm{N}_{2-}$ fixation, or root system quality, showing that selective and specific functional compatibility relationships among the microbial inoculants were evident with respect to plant response.

\section{Quality improvement}

These interactions may contribute to the improvement of food processing, food safety, and quality assurance as well as the development of functional plant products and optimize health and prevent diseases. Plant growth-promoting rhizobacteria (PGPR) Bacillus subtilis (BS2) was effective against 
tomato wilt caused by Fusarium oxysporum $\mathrm{f}$ sp. lycopersici under field conditions. Pretreatment of tomato plants with $B$. subtilis significantly induced the activities of defenserelated enzymes viz., peroxidase, polyphenol oxidase, chitinase, and phenylalanine ammonia-lyase and phenolics when challenged with the pathogen. The defenserelated enzymes play a vital role in lignin biosynthesis, oxidation of phenol and synthesis of antimicrobial phytoalexins (Daayf et al.,1997). BS2 also improved fruit quality and texture. PGPR can also enhance the nutritional quality and shelf life of the plant products.

Phenolics are known to have fungitoxic effects and a role in strengthening the host cell wall. PGPR treated plants showed a high level of accumulation of phenolics when challenged with pathogens. In another study, it has been observed that the inoculation of seeds with useful microorganisms increases the yield and yield components of sunflower plants significantly, as compared to the control treatment (Akbari et al., 2011). Rhizobacterial strains Azospirillum and Azotobacter are ideal candidates for development of bioformulation for the sesamum plants. The study also inferred that ALCF treatment improved plant growth, seed yield, and sesame oil quality. The phytochemicals present in small quantities help in reducing the occurrence of biotic and abiotic diseases in plants. The process of induced cellular defense response is known as priming. Plant exudates containing secondary metabolites help increase in phosphate availability, metals uptake, and defense from environmental stress. Plant synthesizes a great amount of bioactive compounds that get released into rhizosphere that stimulates the biological activities in the zone and thereby, the rhizosphere bacteria, which supply increased nutrients, fixed nitrogen, growth promoting compounds to the plants help to check pathogen invasion as well. Bioactive compounds from microbes have proved to be important for improving plant growth, human health, ultimately enhancing the quality of plant products.

In conclusion the subjugation of the rhizosphere with fungi and bacteria execute various processes that impact plants' victual; hence, it provides a boon to plant growth and vigour. The diversity of microbial communities is responsible for ecosystem stability and has many positive effects on plant growth, disease resistance, and tolerance towards abiotic stresses. Thus, microbial inoculants must be considered for the maintenance of sustainable plant productivity and quality, which will contribute to smart agriculture. Manipulation of these plantmicrobe associations would avail us to determine novel compounds having antagonistic competence against phytopathogens. Moreover, interplays may reveal the occurrence of natural product applications as a sustainable resource thatis nature-friendly.

\section{References}

Akbari, P., A.Ghalavand, A.M Modares, M. Agha Ali Khani, S. ShoghiKalkhoran (2011). Comparsion of different nutritional levels and the effect of plant growth promoting rhizobacteria (PGPR) on the grain yield and quality of sunflower. Australian Journal of Crop Science.5(12):1570-1576.

Ayyadurai, N., Ravindra,Naik., P,Sakthivel. (2007). Functional characterization of antagonistic fluorescent pseudomonads associated with rhizospheric soil of rice (Oryza sativa L.). Journal of Microbiol Biotechnology.17:919-927

Bais, H.P., S.W.Park., T.L. Weir., R.M. Callaway and J.M. Vivanco. 2004. How plants communicate using the 
underground information superhighway. Trends in Plant Sciences.9:26-32.

Barea, J.M., Azcón-Aguilar, C. and Azcón, R. (1997). Interactions between mycorrhizal fungi and rhizosphere microorganisms within the context of sustainable soil-plant systems. In:Gange AC and Brown VK (Eds) Multitrophic Interactions in Terrestrial Systems (pp 65-77). Blackwell Science, Oxford.

Bloemberg, G.V and Lugtenberg, B.J.J. 2001.Molecular basis of plant growth promotion and biocontrol by rhizobacteria.Curr.Opin.Plant Biology.4: 343-350.

Bianciotto, V.,Lumini, E.,Lanfranco, L., Minerdi, D., Bonfante, P. and Perotto, S. (2000).Detection and identification of bacterial endosymbionts in arbuscular mycorrhizal fungi belonging to the family Gigasporaceae. Applied Environmental Microbiology. 66: 45034509.

Bowen, G.D. and Rovira, A.D. (1999). The rhizosphere and its management to improve plant growth. Adv. Agron.66: 1102.

Compant, S. 2005. Use of plant growthpromoting bacteria for biocontrol of plant diseases:principles, mechanisms of action and future prospects. Applied Environmental Microbiology. 71: 49514959.

Calvet, C., Pera, J. and Barea, J.M. (1993). Growth response of marigold (Tagetes erecta L.) to inoculation with Glomus mosseae, Trichoderma aureoviride and Phythium ultimum in a peat-perlite mixture. Plant Soil.148: 1-6.

Ding, L.J., H.L. Cui., S.A.Nie., X.E. Long., G.L. Duan and Y.G. Zhu. 2019. Microbiomes inhabiting rice roots and rhizosphere. FEMS Microbiology Ecology.95(5).

Daayf, F., Bel-Rhlid, R., and B'elanger, R.R.(1997).Methyl ester of pcoumaric acid: A phtoalexin-like compound from long English cucumber leaves. J.Chem. Eco.23: 1517-1526.

Glick, B.R., Bashan, Y.(1997). Genetic manipulation of plant growth-promoting bacteria to enhance biocontrol of fungal phytopathogens. Biotechnol Adv.15:353378

Glick, B.R., Karaturovic, D.M., Newell, P.C.(1995). A novel procedure for rapid isolation of plant growth promoting Pseudomonas. Can J Microbiol.41:533536

Harley, J.L. and Smith, S.E.(1983). Mycorrhizal Symbiosis. Academic Press, New York.

Jin, C.W., He, Y.F., Tang, C.X., Wu, P. and Zheng, S.J. (2006). Mechanism of microbially enhanced Fe acquisition in red clover (Trifolium pratenseL.). Plant Cell Environ.29:888-89

Jha, C.K., Aeron, A., Patel, B.V., Maheshwari, D.K. and Saraf, M.(2011).Enterobacter: role in plant growth promotion. In: Maheshwari DK (ed) Bacteria in agrobiology: plant growth responses. Springer, Heidelberg, pp 159-182

Jaeger, C.H., Lindow, S.E., Miller, W., Clark, E. and Firestone, M.K. (1999). Mapping of sugar and amino acid availability in soil around roots with bacterial sensors of sucrose and tryptophan. Applied Environmental Microbiology.65:26852690.

Kloepper, J.W.,Lifshitz, R., Zablotowicz, R.M. (1989). Free living bacterial inocula for enhancing crop productivity. Trends Biotechnol.7:39-44

Khalid, A., Arshad, M. and Zahir, Z.A. (2006).Phytohormones: microbial production and applications. In: Uphoff $\mathrm{N}$, Ball AS, Fernandes E, Herren H, Husson O, Laing M, Palm C, Pretty J, Sanchez P, Sanginga N, Thies J (eds) Biological approaches to sustainable soil 
systems. Taylor and Francis, Boca Raton, pp 207-220

Lugtenberg, B.J.J., Chin-A-Woeng, T.F.C and Bloemberg, G.V.2002. Microbe-Plant interactions:principles and mechanisms. Antonie Van Leeuwenhoek.81: 373-383.

Nadeem, S.M., M. Naveed., Z.A., Zahir and H.N. Asghar. 2013.Plant-microbe interactions for sustainable agriculture: Fundamentals and Recent Advances.p.53-103. In: Plant Microbe Symbiosis: Fundamentals and Advances.N.Arora (ed.). Springer, India. Nadeem, S.M., M, Ahmad., M, Naveed., M, Imran., Z.A. Zahir and D.E. Crowley. 2016.Relationship between in vitro characterization and comparative efficacy of plant growth-promoting rhizobacteria for improving cucumber salt tolerance. Archives of Microbiology.198: 379-87.

Pamp, S.J. and T.Tolker-Neilsen.2007. Multiple roles of biosurfactants in structural biofilm development by Pseudomonas aeruginosa. Journal of Bacteriology.189:2531-2539.

Parniske, M. 2008.Arbuscular mycorrhiza:The mother of plant root endosymbioses. Nature Reviews Microbiology.6:763-775.

Persello-Cartieaux, F., Nussaume, L. and Robaglia, C.(2003). Tales from the underground: molecular plantrhizobacterial interactions. Plant Cell Environ.26:189-199

Ravindra,Naik., P, Raman., G, Badri., Narayanan, K and Sakthivel, N.(2008). Assessment of genetic and functional diversity of phosphate solubilizing fluorescent pseudomonads isolated from rhizospheric soil. BMC Microbiol.8:230

Robin, A., Vansuyt, G., Hinsinger, P., Meyer, J., Briat, J. and Lemanceau, P. (2008). Iron dynamics in the rhizosphere: consequences for plant health and nutrition. Adv Agron.99:183-22
Saharan, B., and V. Nehra. 2011.Plant growth promoting rhizobacteria:A critical review. International Journal of Statistics in Medical Research21:1-30.

Schikora, A.2018. Plant-microbe Interactions in the Rhizosphere. Caister Academic Press, Braunschweig, Germany.

Singh, N., Kumar, S., Bajpai, V.K., Dubey, R.C., Maheshwari, D.K. and Kang, S.C.(2010b). Biocontrol of Macrophomina phaseolina by chemotactic fluorescent Pseudomonas aeruginosa PN1 and its plant growth promontory activity in chir pine. Crop Prot.29:1142-1147

Smith, S.E., Gianinazzi-Pearson, V., Koide, R. and Cairney, J.W.(1994). Nutrient transport in mycorrhizas: structure, physiology and consequences for efficiency of the symbiosis.In: Robson $\mathrm{AD}$, Abbott LK andMalajczuk N (Eds) Management of Mycorrhizas in Agriculture, Horticulture and Forestry (pp 103-113). Kluwer Academic Publishers, Dordrecht

Spaepen, S., Vanderleyden, J. and Okon,Y.(2009). Plant growth-promoting actions of rhizobacteria. Adv Bot Res. 51:283-320

Smith, D.E and Read, D.J. (1997). Mycorrhizal Symbiosis. Academic Press. London.

Vessey, J.K. (2003). Plant growth promoting rhizobacteria as biofertilizers. Plant Soil.255:571-586

Vázquez, M.M., Cesar, S., Azcón, R. and Barea, J.M.(2000). Interactions between arbuscular mycorrhizal fungi and other microbial inoculants (Azospirillum, Pseudomonas, Trichoderma) and their effects on microbial population and enzyme activities in the rhizosphere of maize plants. Appl. Soil.Ecol. 15: 261272.

Vacheron,J., G. Desbrosses, M.Bouffaud, B. Touraine.,Y. Moenne-Loccoz., D. 
Muller., L. Lengendre., F. WisniewskiDye and C. Prigent-Combaret.2013. Plant growth-promoting rhizobacteria and root system functioning.Frontier in Plant Sciences. 4:1-19.

Wille, L., M.M. Messmer, B. Studer and P. Hohmann. 2019. Insights to plantmicrobe interactions provide oppurtunities to improve resistance breeding against root diseases in grain legumes. Plant, Cell and Environment. 42(1):20-40.
Whipps, J.M.2001. Microbial interactions and biocontrol in the rhizosphere. $J$. Exp.Bot.52:487-511

Xiong, K. and J.J Fuhrmann.1996. Comparison of rhizobitoxine-induced inhibtion of beta-cystathionase from different bradyrhizobia and soybean genotypes.p.53-61. In:Current Issues in Symbiotic Nitrogen Fixation. G.H. Elkan, and R.G. Upchurch (eds.). Springer, Netherlands.

\section{How to cite this article:}

Tabish Shabir, Zahoor A. Baba, Shakeel A. Dar and Amjad M. Husaini 2020. Improving Plant Growth and Quality of Plant-Products: An Interplay of Plant-microbe Interaction. Int.J.Curr.Microbiol.App.Sci. 9(11): 3759-3766. doi: https://doi.org/10.20546/ijcmas.2020.911.451 